\title{
Intestinal T lymphocyte homing is associated with gastric emptying and epithelial barrier function in critically ill: a prospective observational study
}

Christian Greis $^{1 \dagger}$, Zohal Rasuly ${ }^{1 \dagger}$, Rolf A. Janosi ${ }^{2}$, Lambros Kordelas ${ }^{1}$, Dietrich W. Beelen ${ }^{1}$ and Tobias Liebregts ${ }^{1 *}$

\begin{abstract}
Background: Impaired gastric emptying is common in critically ill patients. Intestinal dysmotility, a major cause of feed intolerance, may foster infectious complications due to mucosal barrier disruption. However, little is known about gut-directed immune activation, intestinal barrier function and its association with impaired gastric emptying in critically ill patients at ICU admission.

Methods: We conducted a prospective observational study at two tertiary care medical ICUs. Fifty consecutive patients needing invasive mechanical ventilation were recruited within $24 \mathrm{~h}$ of ICU admission, prior to any nutritional support. The acute physiology and chronic health evaluation (APACHE) II score, the sequential organ failure assessment (SOFA) score and the multiple organ dysfunction score (MODS) were used to assess illness severity and multiple organ dysfunction. Gastric emptying was assessed by paracetamol absorption test. Peripheral blood mononuclear cells were freshly isolated and cultured for $24 \mathrm{~h}$, and TNF- $\mathrm{a}, \mathrm{IL}-1 \beta$ and IL-10 measured in cell culture supernatants and in serum by ELISA. The intestinal epithelial barrier was assessed, quantifying serum concentrations of intestinal fatty acid binding protein (I-FABP), ileal bile-acid binding protein (I-BABP) and zonulin-1 by ELISA. Small bowel homing T lymphocytes (CD4+ a4ß37+CCR9+) were analyzed by flow cytometry. The MannWhitney test and Spearman correlation were used in statistical evaluation.
\end{abstract}

Results: CD4 + a4 $37+C C R 9+T$ lymphocytes were inversely correlated with gastric emptying. Patients with delayed gastric emptying at ICU admission $(n=35)$ had significantly higher serum and PBMC-induced TNF- $a$ and IL-1 $\beta$ and increased intestinal barrier disruption reflected by higher I-FABP, I-BABP and zonulin-1. Patients who died in the ICU had significantly impaired gastric empting at admission compared to ICU survivors. No differences were observed in APACHE II, SOFA or MODS in patients with delayed gastric emptying compared to patients with normal gastric emptying.

Conclusions: Exaggerated CD4 + a4ß7 + CCR9+ T lymphocyte homing with increased pro-inflammatory cytokine release and intestinal epithelial barrier disruption are associated with delayed gastric emptying. This is not simply due to differences in overall severity of illness at ICU admission and may represent a pathophysiological mechanism of gut-directed immune activation leading to impaired barrier function in the critically ill.

Keywords: Gastric emptying, Gut homing, Mucosal barrier, T lymphocytes, Intensive care, Critically ill

\footnotetext{
* Correspondence: tobias.liebregts@uk-essen.de

†Equal contributors

${ }^{1}$ Department of Bone Marrow Transplantation, University of Duisburg-Essen, University Hospital Essen, West German Cancer Center, Hufelandstr. 55, Essen 45122, Germany

Full list of author information is available at the end of the article
} International License (http://creativecommons.org/licenses/by/4.0/), which permits unrestricted use, distribution, and reproduction in any medium, provided you give appropriate credit to the original author(s) and the source, provide a link to the Creative Commons license, and indicate if changes were made. The Creative Commons Public Domain Dedication waiver (http://creativecommons.org/publicdomain/zero/1.0/) applies to the data made available in this article, unless otherwise stated. 


\section{Background}

Enteral nutrition via the gastrointestinal tract is accepted to improve health outcomes in critically ill patients [1]. Gastrointestinal motility disorders, in particular impaired gastric emptying frequently impede enteral nutrient delivery. The advantages of enteral nutrition include a decrease in infectious complications and mucosal barrier protection against bacterial translocation [2, 3]. The highest incidence of delayed gastric emptying in the critically ill has been reported in patients with sepsis [4].

The intestine participates in the inflammatory response locally with cytokine production and leukocyte recruitment. To perform their immunological functions, $\mathrm{T}$ lymphocytes must exit the blood and enter into different tissues in the body. Recruitment of leukocytes during an inflammatory response involves the expression and activation of adhesion molecules. CD4 $+\mathrm{T}$ lymphocytes responding to the antigen in intestinal lymph nodes start to express high levels of the integrin $\alpha 4 \beta 7$ and the chemokine receptor CCR9. The intestinal ligand of CCR9 is CCL25 and it is mainly expressed in the mucosal epithelium of the small intestine. Thus, co-expression of $\alpha 4 \beta 7$ and CCR9 delineates a subset of $\mathrm{T}$ lymphocytes preferentially migrating to the lamina propria of the small intestine [5].

While we have previously identified association between CD4 + $\alpha 4 \beta 7+C C R 9+T$ lymphocytes and gastric emptying [6], we hypothesized that CD $4+\alpha 4 \beta 7+\mathrm{CCR} 9+\mathrm{T}$ lymphocytes are associated with enhanced proinflammatory cytokine secretion, intestinal barrier disruption and delayed gastric emptying in the critically ill. While assessment of gastrointestinal permeability by the frequently applied sugar absorption tests are not reliable in ICU patients [7] we choose to quantify plasma zonulin, ileal bile acid binding protein (ileal bile-acid binding protein) and intestinal fatty acid binding protein (intestinal fatty acid binding protein). Scintigraphy is considered the gold standard for evaluation of gastric emptying. Unfortunately, all currently available tests for the assessment of gastrointestinal motility, including scintigraphy, have limited value in the ICU setting. Major obstacles include lengthy procedures, the need to transfer patients, lack of accuracy in multi-organ dysfunction, costs and availability [8]. In the present prospective observational study, we have chosen the paracetamol absorption test for the assessment of gastric emptying as it is a feasible and reliable technique in the ICU setting $[9,10]$.

\section{Methods}

\section{Study population}

Fifty consecutive critically ill patients with immediate need of invasive mechanical ventilation were recruited within $24 \mathrm{~h}$ of ICU admission. A blood sample was drawn from these patients for cell isolation, serum cytokine ELISA and t0 paracetamol concentration measurement followed by immediate application of paracetamol for assessment of gastric emptying. None of these patients received any enteral or parenteral nutritional support within $24 \mathrm{~h}$ of ICU admission. Patients receiving any pro-kinetic drug within 7 days prior to admission were not included.

The leading cause of ICU admission was sepsis, acute respiratory failure or cardiac failure (Table 1). Patients with an underlying malignancy and relapse or disease progression or hematopoietic stem cells recipients with acute graft versus host disease were not included. No surgical or postoperative patients were included. The study was approved by the University Hospital Essen Human Ethics Committee and conducted in accordance with the World Medical Association Declaration of Helsinki. Informed consent was obtained from each patient's next of kin. In addition eligibility for study participation was confirmed by an independent physician.

\section{ICU severity scores}

Severity of illness was assessed by the acute physiology and chronic health evaluation (APACHE) II score and the severity of multiple organ dysfunction was assessed by sequential organ failure assessment (SOFA) and the multiple organ dysfunction score (MODS).

\section{Gastric emptying}

Gastric emptying was assessed by the paracetamol absorption test [9]. Briefly, 2 g paracetamol was administered with $20 \mathrm{ml}$ water via a nasogastric tube. Blood samples were drawn a time $(t)=0,15,30,60,90$ and 120 minutes to measure paracetamol levels determined by the enzymatic degradation method. The area under the concentration curve from 0 to $60 \mathrm{mi}$ nutes (AUC60) was used as the measure of gastric emptying. An AUC $<600 \mathrm{~min}^{*} \mathrm{mg} / \mathrm{l}$ was considered as delayed gastric emptying [9].

\section{Cell isolation and culture conditions}

For the following cell culture and ELISA experiments investigators were blinded to study subject details, including diagnosis, age and gender. Peripheral blood mononuclear cells (PBMC) were freshly isolated by density gradient centrifugation. Diluted blood (1:2 in RPMI 1640 medium) was layered onto Ficoll-Hypaque (Sigma, Castle Hill, NSW, Australia) and centrifuged at $400 \mathrm{~g}$ for 15 minutes. PBMC were washed twice with sterile PBS and viability was assessed by trypan blue exclusion. PBMC were resuspended to $1 \times 10^{6}$ cells $/ \mathrm{ml}$ in complete medium (RPMI 1640 medium (Gibco, Karlsruhe, Germany), supplemented with $10 \%$ fetal calf serum, $100 \mathrm{U} / \mathrm{ml}$ penicillin, $0.1 \mathrm{mg} / \mathrm{ml}$ streptomycin and L-Glutamine). PBMC were cultured in 24-well plates for $24 \mathrm{~h}$. 
Table 1 Patient characteristics

\begin{tabular}{|c|c|c|}
\hline & $\begin{array}{l}\text { Delayed gastric } \\
\text { emptying } \\
(n=35)\end{array}$ & $\begin{array}{l}\text { Normal gastric } \\
\text { emptying } \\
(n=15)\end{array}$ \\
\hline \multicolumn{3}{|l|}{ Demographics } \\
\hline Age (years) & $58.4 \pm 15.2$ & $62.1 \pm 11.4$ \\
\hline Gender (male/female), $n$ & $17 / 18$ & $8 / 7$ \\
\hline Body mass index $\left(\mathrm{kg} / \mathrm{m}^{2}\right)$ & $27.6 \pm 7.3$ & $27.3 \pm 6.2$ \\
\hline \multicolumn{3}{|l|}{ Admission diagnosis, $n$ (\%) } \\
\hline Sepsis & $13(37)$ & $7(47)$ \\
\hline Acute respiratory failure & $12(34)$ & $5(33)$ \\
\hline Cardiac failure & $10(29)$ & $3(20)$ \\
\hline \multicolumn{3}{|l|}{ Underlying condition } \\
\hline Hematologic malignancies, n (\%) & $17(49)$ & $7(47)$ \\
\hline$\triangleright$ Acute myeloid leukemia & $11(64)$ & $4(58)$ \\
\hline$\triangleright$ Lymphoma (B cell) & $2(12)$ & $1(14)$ \\
\hline$\triangleright$ Myelodysplasia & $2(12)$ & $1(14)$ \\
\hline$\triangleright$ Myeloproliferative disease & $1(6)$ & $1(14)$ \\
\hline$\triangleright$ Multiple myeloma & $1(6)$ & 0 \\
\hline Solid tumors & $5(14)$ & $4(26)$ \\
\hline $\mathrm{HSCT}$ & $4(11)$ & $1(7)$ \\
\hline Cardiac ischemia & $6(17)$ & $2(13)$ \\
\hline Solid organ transplant & $3(9)$ & $1(7)$ \\
\hline \multicolumn{3}{|l|}{ Renal function, $n(\%)$} \\
\hline Failure & $16(46)$ & $6(40)$ \\
\hline Renal replacement therapy & $9(26)$ & $5(33)$ \\
\hline \multicolumn{3}{|l|}{ Biochemistry } \\
\hline Serum bilirubin level (mg/dl) & $1.4 \pm 1.8$ & $0.9 \pm 0.7$ \\
\hline White blood cell count (/nl) & $8.8 \pm 6.4$ & $10.8 \pm 7.1$ \\
\hline Serum creatinine (mg/dl) & $1.2 \pm 1.4$ & $0.9 \pm 1.1$ \\
\hline \multicolumn{3}{|l|}{ Glycemic control } \\
\hline Blood glucose level (mg/dl) & $124.0 \pm 39.0$ & $143.3 \pm 24.1$ \\
\hline Insulin (IE/h) & $2.6 \pm 5.3$ & $1.8 \pm 2.2$ \\
\hline \multicolumn{3}{|l|}{ Medications, n (\%) } \\
\hline Sufentanil & $35(100)$ & $15(100)$ \\
\hline Midazolam & $26(74)$ & $11(73)$ \\
\hline Propofol & $9(26)$ & $4(27)$ \\
\hline Vasoactive drugs & $23(66)$ & $12(80)$ \\
\hline Inotropes & $10(29)$ & $5(33)$ \\
\hline \multicolumn{3}{|l|}{ Mechanical ventilation } \\
\hline $\mathrm{PaO}_{2} / \mathrm{FiO}_{2}$ ratio & $213.2 \pm 76.4$ & $229.1 \pm 96.2$ \\
\hline Peak inspiratory pressure $(\mathrm{mmHg})$ & $22.6 \pm 4.9$ & $23.3 \pm 3.2$ \\
\hline $\begin{array}{l}\text { Positive end-expiratory pressure } \\
(\mathrm{mmHg})\end{array}$ & $7.8 \pm 2.9$ & $7.7 \pm 2.8$ \\
\hline ICU length of stay (days) & $33.8 \pm 30.1$ & $24.7 \pm 18.1$ \\
\hline
\end{tabular}

Results are presented as mean \pm SD or number (percentage). HSCT allogeneic hematopoietic stem cell transplantation, $\mathrm{PaO}_{2} / \mathrm{FiO}_{2}$ partial arterial oxygen pressure/fraction of inspired oxygen
ELISA

Serum and cell-free culture supernatants were collected, diluted in the supplied dilution buffer or 1:1 in RPMI medium and stored at $-80{ }^{\circ} \mathrm{C}$ until assayed. TNF- $\alpha$, IL$1 \beta$ and IL-10 were quantified using ELISA kits (eBioscience, San Diego, CA, USA) according to the manufacturer's instructions with minor modifications. Human I-FABP (Hycultbiotech, Beutelsbach, Germany), Zonulin and I-BABP (Cusabio, Wuhan, China) were analyzed utilizing commercially available ELISA kits. Optical density was measured at a wavelength of $450 \mathrm{~nm}$ and a reference wavelength of $590 \mathrm{~nm}$. Density values were linearly correlated with the concentrations of test standards.

\section{Flow cytometry}

To identify small bowel homing $\mathrm{T}$ lymphocytes freshly isolated PBMC $\left(10^{5}\right)$ were labeled with previously determined optimal concentrations of monoclonal antibodies directed against human CD3 (APC; eBioscience), CD4 (PerCp; eBioscience), CD49d ( $\alpha 4$-Integrin) (FITC; BioLegend), $\beta 7$-Integrin (PE; BioLegend) and CCR9 (Alexa647; BioLegend). Matching IgG1 and IgG2a conjugated antibodies served as isotype controls. Cells were incubated with the antibodies for 30 minutes on ice and washed three times in FACS buffer between each step. Nonspecific binding of antibodies was minimized by 10 -minute incubation of cell suspensions with pooled human serum $(10 \%)$ in fluorescence-activated cell sorting (FACS) buffer before addition of the first antibody. After washing twice, cells were re-suspended in $100 \mu \mathrm{l}$ of $1 \%$ paraformaldehyde in PBS and analyzed utilizing a Beckman Coulter Navios. Lymphocyte populations were gated based on forward scatter/side scatter properties. A total of $3 \times 10^{4}$ events were routinely collected and analyzed.

\section{Data analysis}

The non-parametric Wilcoxon rank-sum test was used to evaluate differences between groups according to normal and delayed gastric emptying reflected by paracetamol absorption below or above $600 \mathrm{~min} * \mathrm{mg} / \mathrm{l}$ and ICU survival. Data are expressed as median, $95 \%$ confidence interval; throughout the manuscript, $n$ represents the number of subjects. The relationship between CD4 $+\alpha 4 \beta 7+$ CCR9+ $\mathrm{T}$ lymphoctyes and paracetamol absorption was assessed by Spearman rank correlation. In all cases $p$ values $<0.05$ were considered significant. SPSS Version 12 (Statistical Package for Social Sciences, Chicago, I, USA) was used for the statistical analysis.

\section{Results}

Patient characteristics

Patient demographics are displayed in Table 1. Dosage of vasoactive drugs, inotropes and sedative or analgesic 
agents did not differ significantly between patients with and without delayed gastric emptying. No differences were observed in age, gender, body mass index (BMI), biochemical measurements, glycemic control or mechanical ventilation parameters. All patients were initially ventilated with biphasic positive airway pressure. $\mathrm{Pa}-$ tients with and without delayed gastric emptying did not differ in the incidence of acute renal failure or need of continuous renal replacement therapy.

\section{Gastric emptying}

There were 35 patients (70\%) with impaired paracetamol absorption, which was used as a measure of delayed gastric emptying at ICU admission. Gastric emptying was significantly ( $p=0.004)$ different (Fig. 1$)$ in patients who died in the ICU (AUC $323.8 \pm 48.1$ ) compared to ICU survivors $(647.4 \pm 93.5)$. Overall mortality in the ICU was $50 \%$.

\section{ICU severity scores}

There were no significant differences in the APACHE II (27.5, $95 \%$ CI $18.0-34.0$ vs. $24.0,95 \%$ CI $19.0-30.0 ; p=$ $0.180)$, SOFA $(10.0,95 \%$ CI $5.0-17.0$ vs. $10.0,95 \%$ CI $4.0-19.0 ; p=0.840)$ or MODS $(9.0,95 \%$ CI $5.0-13.0$ vs. 9.0, 95\% CI 4.0-17.0; $p=0.380)$ in patients with delayed gastric emptying compared to patients with normal gastric emptying (Fig. 2).

\section{Small bowel homing T lymphocytes}

$\mathrm{CD} 4+\alpha 4 \beta 7+\mathrm{CCR} 9+\mathrm{T}$ lymphocytes were inversely correlated $(r=-0.5 ; p=0.001)$ with gastric emptying as reflected by paracetamol absorption (Fig. 3).

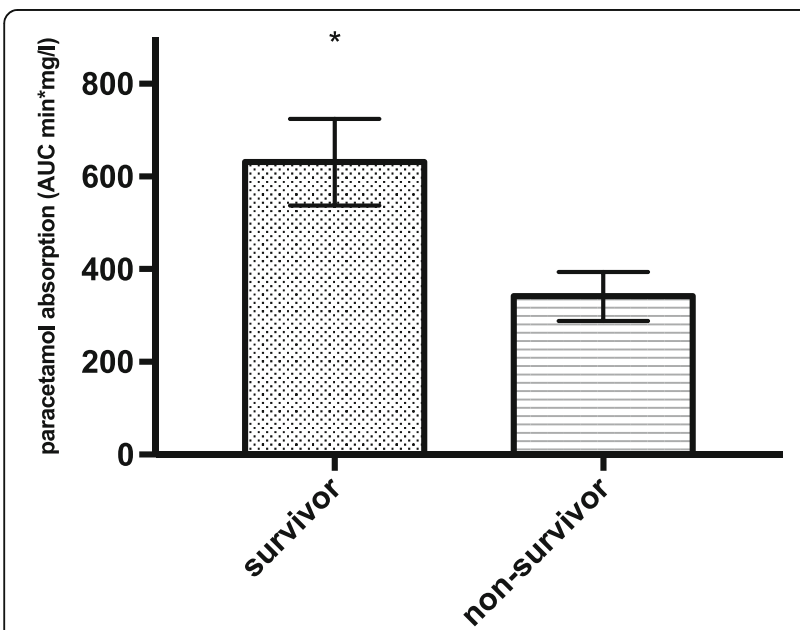

Fig. 1 Paracetamol absorption in ICU survivors compared to nonsurvivors. Patients who died in the ICU had significantly lower paracetamol absorption $(p=0.004)$. AUC area under the curve

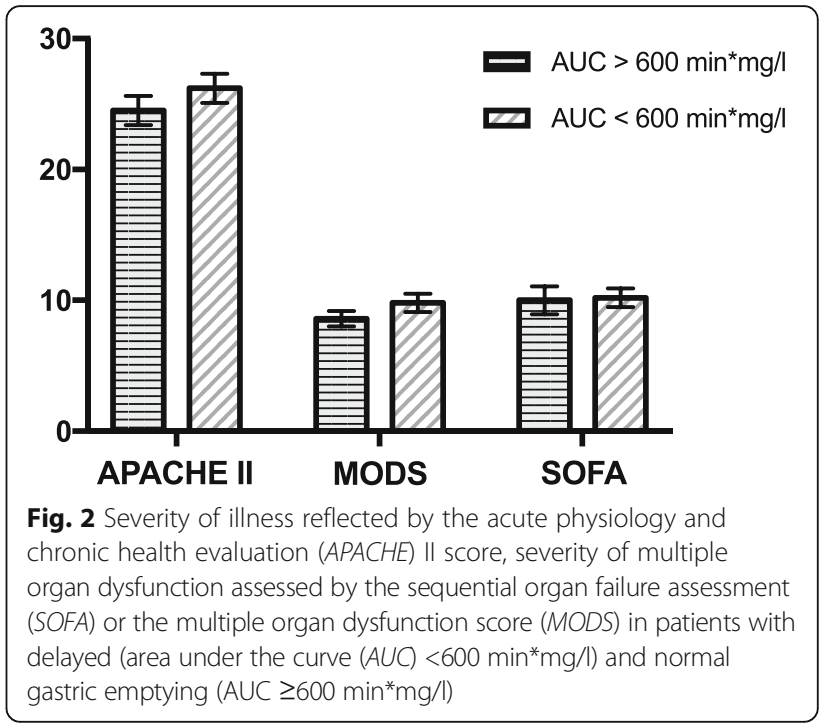

Cytokines

Patients with delayed gastric emptying had significantly enhanced serum TNF- $\alpha(54.0 \mathrm{pg} / \mathrm{ml}, 95 \%$ CI $13.0-127.9$ vs. $28.2 \mathrm{pg} / \mathrm{ml}, 95 \%$ CI $21.8-48.4 ; p=0.022)$ and IL-1 $\beta$ $(98.5 \mathrm{pg} / \mathrm{ml}, 95 \%$ CI $37.0-182.6$ vs. $212.2 \mathrm{pg} / \mathrm{ml}, 95 \%$ CI 91.0-548.6; $p=0.005$ ) compared to patients with normal gastric emptying. Release of PBMC-mediated TNF- $\alpha$ $(86.5 \mathrm{pg} / \mathrm{ml}, 95 \%$ CI $17.4-342.2$ vs. $41.5 \mathrm{pg} / \mathrm{ml}, 95 \%$ CI 31.9-98.6; $p=0.020)$ and IL-1 $\beta(280.4 \mathrm{pg} / \mathrm{ml}, 95 \% \mathrm{CI}$ $94.0-412.5$ vs. $124.6 \mathrm{pg} / \mathrm{ml}, 95 \%$ CI $85.3-247.3 ; p=$ 0.001 ) was significantly augmented in patients with delayed gastric emptying. No significant differences in IL10 were observed (Fig. 4).

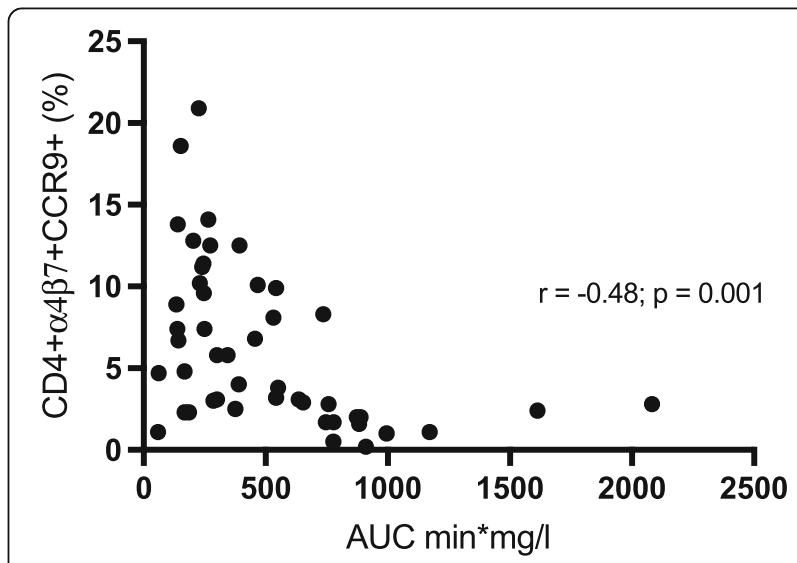

Fig. 3 Percentage of CD4 + $a 4 \beta 7+C C R 9+T$ lymphocytes was inversely correlated $(r=-0.5 ; p=0.001)$ with gastric emptying as reflected by paracetamol absorption (area under the curve (AUC) $\mathrm{min}^{*} \mathrm{mg} / \mathrm{l}$ ) 

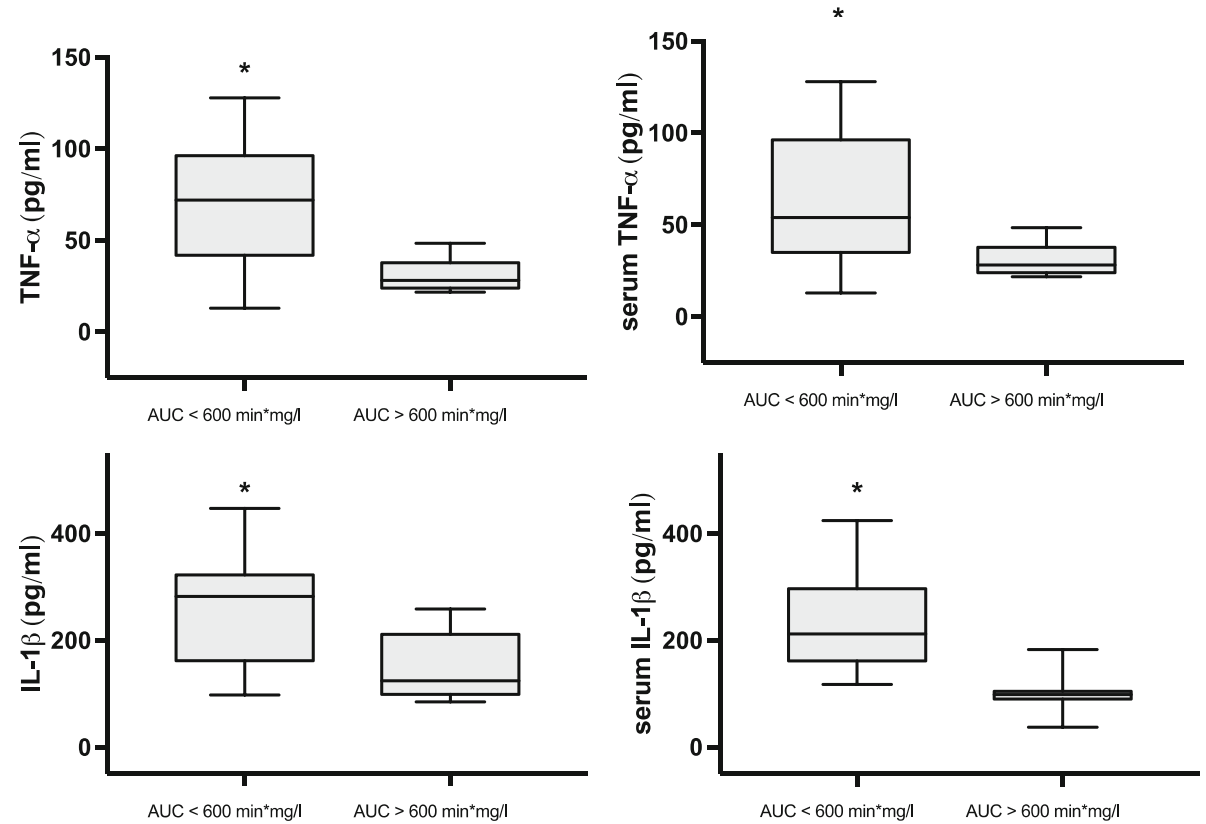

Fig. $4 \mathrm{TNF}-\alpha$ and $\mathrm{IL}-1 \beta(\mathrm{pg} / \mathrm{ml})$ in peripheral blood mononuclear cell culture supernatants and serum of patients with delayed gastric emptying (area under the curve (AUC) $<600 \mathrm{~min}^{*} \mathrm{mg} / \mathrm{l}$ ) and normal gastric emptying (AUC $\left.\geq 600 \mathrm{~min}^{*} \mathrm{mg} / \mathrm{l}\right)$. Error bars range, bold line median, box 5th-95th centiles)

\section{Mucosal integrity}

Delayed gastric emptying was associated with significantly enhanced zonulin $(10.4 \mathrm{ng} / \mathrm{ml}, 95 \%$ CI $0.5-59.0$ vs. $2.5 \mathrm{ng} / \mathrm{ml}, 95 \% 0.6-4.9 ; p=0.020)$, I-BABP $3.7 \mathrm{ng} / \mathrm{ml}$, 95\% CI $0.7-7.8$ vs. $1.0 \mathrm{ng} / \mathrm{ml}, 95 \%$ CI $0.6-1.3 ; p=0.015$ ) and I-FABP $(592.0 \mathrm{pg} / \mathrm{ml}, 95 \%$ CI $218.0-975.0$ vs. 244.5 pg/ml, 95\% CI 180.0-567.0; $p=0.009$ ) (Fig. 5).

\section{Discussion}

The inability of enteral feeding due to delayed gastric emptying frequently necessitates total parenteral nutrition. Total parenteral nutrition itself leads to mucosal inflammatory response resulting in a loss of epithelial barrier function [2], further contributing to intestinal motility disturbances. Increased intestinal permeability predicts the development of multiple organ failure and early enteral nutrition is a key factor for preservation of gut barrier function reducing the risk of organ failure [11]. Furthermore, enterocyte damage has been reported to be associated with ICU mortality [12].

While in most studies feed-intolerant patients or patients receiving parenteral nutrition have been examined, we investigated immune activation with epithelial barrier dysfunction and gastric emptying at admission prior to any enteral or parenteral nutritional support. Zonulin increases intestinal permeability in the epithelia of the small intestine and increased plasma zonulin has been reported in sepsis [13]. I-FABP is particularly expressed in the jejunum and if released into plasma indicates enterocyte destruction $[14,15]$, while I-BABP is exclusively present in the ileum [16]. We identified increased Zonulin, I-BABP and I-FABP levels in patients with delayed gastric emptying, indicating marked differences in upper gastrointestinal mucosal barrier integrity at the onset of critical illness.

In our study patients with delayed gastric emptying had significantly higher CD $4+\alpha 4 \beta 7+C C R 9+T$ lymphocytes compared to patients with normal gastric emptying at ICU admission. Indeed CCR9 is required for effector $\mathrm{CD} 4+\mathrm{T}$ lymphocyte entry into small intestinal lamina propria [17]. Under inflammatory conditions intraepithelial lymphocytes alter barrier function, consequently enhancing intestinal permeability and further enhancing chemokine production [18]. In particular, IFABP and IBAP were inversely correlated with gastric emptying, indicating small bowel immune activation with intestinal barrier alterations associated with gastric emptying. There is further evidence linking intestinal immune activation with $\mathrm{CD} 4+\alpha 4 \beta 7+\mathrm{CCR} 9+\mathrm{T}$ lymphocytes and gastrointestinal motility. The detection of CCR9-expressing $\mathrm{T}$ lymphocytes in the bloodstream of patients with post-operative ileus has been reported to potentially reflect dysmotility [19].

Apart from increased CD4 $+\alpha 4 \beta 7+\mathrm{CCR} 9+\mathrm{T}$ lymphocytes, we also identified increased serum cytokine levels and pro-inflammatory cytokines produced in vitro by PBMC. Intestinal dysmotility is known to be accompanied by increased expression of pro-inflammatory 


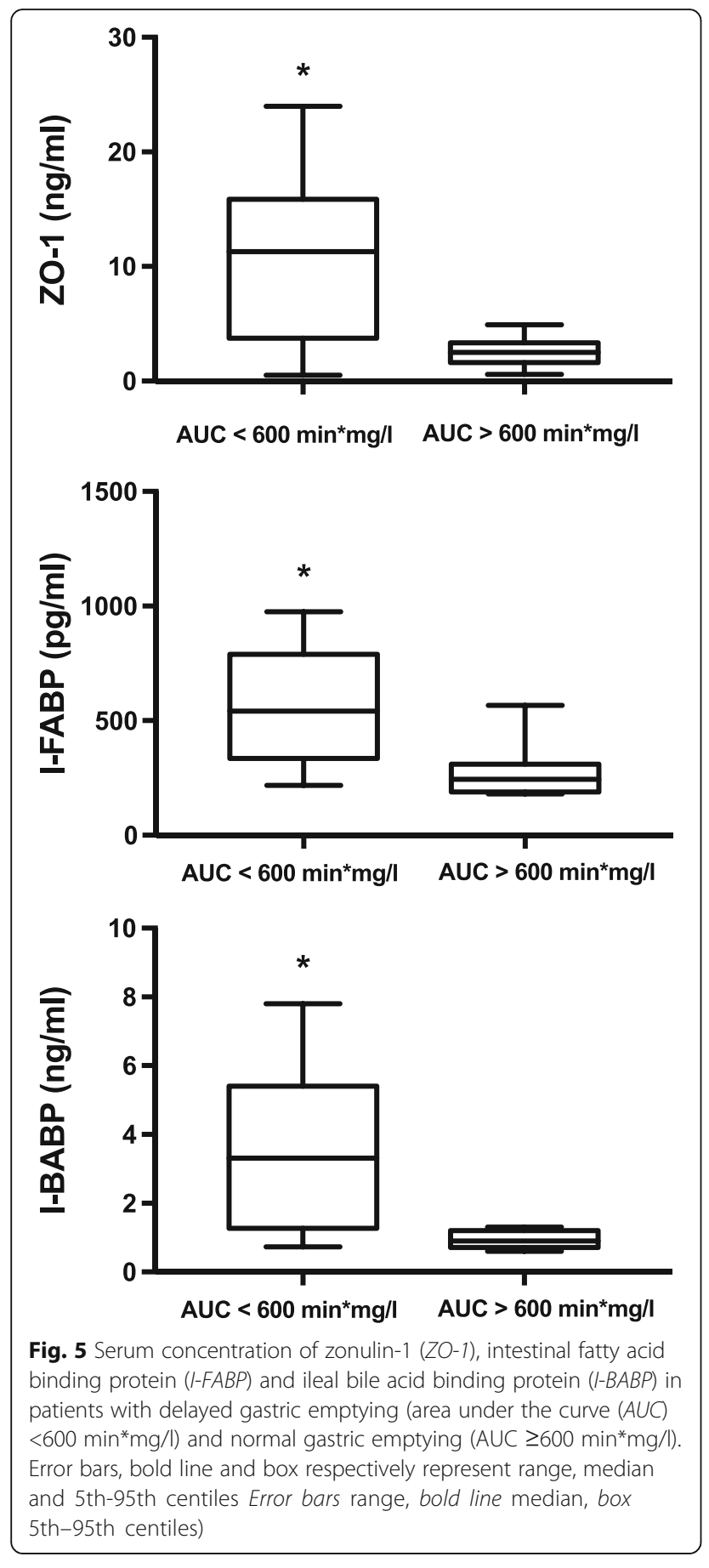

cytokines such as TNF- $\alpha$ and IL- $1 \beta$, followed by infiltration of lymphocytes [20]. Based on animal models, TNF$\alpha$ and IL-1 $\beta$ are known to directly inhibit gastric emptying [21] and decrease small bowel muscle contractility [22]. The increased release of pro-inflammatory cytokines is followed by infiltration of $\mathrm{T}$ lymphocytes and macrophages [23]. Macrophages activated by CD4+ $\mathrm{T}$ lymphocytes in the intestine initiate the release of nitric oxide, directly inhibiting smooth muscle cell function [24] consequently contributing to intestinal dysmotility. In a previous study, both cytokines were enhanced in patients with idiopathic gastroparesis even in the absence of an infectious stimulus [6]. Thus, our data clearly suggest an association between increased proinflammatory cytokines with delayed gastric emptying in the critically ill. Furthermore, TNF- $\alpha$ is a critical factor for epithelial barrier dysfunction [25]. A significant increase in TNF- $\alpha$ in bowel segments is linked to an impaired epithelial barrier [3] within these segments. We therefore believe that our findings of enhanced epithelial barrier function reflected by increased zonulin, I-BABP and I-FABP in subjects with delayed gastric emptying depict a putative causal link between initial immune activation and gastric dysmotility.

Utilizing the paracetamol absorption test, we found $70 \%$ of patients, who were admitted to the ICU and needed immediate invasive mechanical ventilation, had impaired gastric emptying. This is in line with published data showing delayed gastric emptying in $42-81 \%$ of ICU patients [26, 27]. While the diagnosis on admission exerts a modest impact on gastric emptying in the critically ill, it appears to be most prominent in sepsis. Indeed, the majority of patients included in the present study were admitted to ICU with an infectious complication leading to sepsis or acute respiratory failure. Against the background of published data demonstrating an association between gastric emptying and severity of illness [4] it could be argued that the observed differences in immune activation and epithelial barrier function parameters between patients with normal and delayed gastric emptying are simply a function of baseline severity of illness. However, we did not observe differences in the APACHE II, MODS or SOFA in our study population.

Other potentially confounding factors include sedation and glycemic control. It has been demonstrated that patients receiving morphine and midazolam are more likely to have slow gastric emptying than those receiving propofol [28]. The majority of the patients included in our study received midazolame and sufentanil, without significant differences between the groups. However, an effect of sedation on the overall rate of delayed gastric emptying cannot be excluded. There is abundant literature on glycemic control in the critically ill and blood glucose concentration could be one of a number of factors affecting gastric emptying [29]. Our patients had comparable blood glucose levels and equal insulin doses to achieve glycemic control. Therefore, a profound effect on gastric emptying cannot be assumed.

It also needs to be acknowledged that the majority of patients in our study had an underlying malignancy. There are some data indicating $\mathrm{T}$ lymphocyte dysfunction in patients with hematologic malignancies, potentially differing from the general population of critically ill patients. 
Different degrees of $\mathrm{T}$ lymphocyte dysfunctionality, including impaired proliferation, altered cytokine secretion and altered expression of surface molecules, have been described in various hematologic malignancies. In particular T cell lymphoma, chronic myeloid leukemia and chronic lymphoid leukemia are known to be associated with $\mathrm{T}$ lymphocyte dysfunctionality. The invasive spreading ability of leukemic cells may depend on the expression of surface molecules including $\alpha 4 \beta 7$-Integrin.

There are limited data on neoplastic cells in $\mathrm{T}$ cell lymphoma, not achieving remission, expressing $\alpha 4 \beta 7$ Integrin when infiltrating bone marrow [30]. Increased expression of $\alpha 4 \beta 7$-Integrin is also observed in hematopoietic stem cell recipients with acute gastrointestinal graft versus host disease [31]. Therefore, it needs to be emphasized that we did not include patients with relapse, disease progression or acute graft versus host disease in this study. In addition, the majority of patients with an underlying hematological malignancy had acute myeloid leukemia, which is not associated with a $\mathrm{T}$ lymphocyte proliferation defect or impairment of cytokine secretion [32]. Furthermore patients in remission or patients who have undergone intensive chemotherapy may have reduced CD4+ T lymphocytes but without impairment of proliferation [33]. Only when $\mathrm{T}$ lymphocyte counts are very low are the remaining $\mathrm{T}$ lymphocytes functionally impaired. Thus, it is important to emphasize that patients in our study had normal white blood cell counts and T lymphocyte populations and therefore do not represent severely

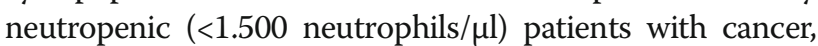
whose inclusion could potentially confound the immune activation results. However, the observed ICU mortality of $50 \%$ reflects current mortality rates of critically ill patients with cancer [34] and is therefore certainly due to the high percentage of patients in our study who had malignancies.

\section{Conclusions}

To our knowledge this study is the first to identify a link between gastric dysmotility and increased small boweldirected immune activation and mucosal barrier impairment in ICU patients at the onset of critical illness, in the absence of any nutritional support. Our result suggests that initial immune activation leads to increased release of pro-inflammatory cytokines followed by infiltration of lymphocytes. While cytokines are able to directly impair gastrointestinal motility, lymphocytes may contribute to delayed gastric emptying by activating macrophages releasing nitric oxide as a motility inhibitor. Cytokines also impair intestinal permeability, leading to amplification of the inflammatory response. Thus, this cascading inflammation may drive organ failure including impaired intestinal barrier and motility as an underlying cause of further intestinal dysfunction, regardless of the overall severity of the initial illness.

\section{Abbreviations}

APACHE II: Acute physiology and chronic health evaluation score; AUC60: Area under the concentration curve from 0 to 60 minutes; ELISA: Enzyme-linked immunosorbent assay; FACS: fluorescence-activated cell sorting; HSCT: Allogeneic hematopoietic stem cell transplantation; I-BABP: Ileal bile-acid binding protein; I-FABP: Intestinal fatty acid binding protein;

IL: Interleukin; MODS: Multiple organ dysfunction score; PBMC: Peripheral blood mononuclear cells; PBS: phosphate-buffered saline; RPMI: Roswell Park Memorial Institute medium; SOFA: Sequential organ failure assessment; TNF: Tumor necrosis factor

\section{Acknowledgements \\ Not applicable.}

\section{Funding}

Not applicable.

\section{Availability of data and materials}

The datasets during and/or analyzed during the current study are available from the corresponding author on reasonable request.

\section{Authors' contributions}

$T L, D W B, C G$ and RAJ participated in the study conception and design. CG, ZR, RAJ, LK and TL participated in data acquisition. TL and DWB performed data analysis and interpretation. TL drafted the manuscript with all authors revising it critically for intellectual content. All authors approved the version to be published and take responsibility for the content.

\section{Competing interests}

The authors declare that they have no competing interests.

\section{Consent for publication}

Not applicable.

\section{Ethics approval and consent to participate}

The study was approved by the University Hospital Essen Human Ethics Committee and conducted in accordance with the World Medical

Association's Declaration of Helsinki. Informed consent was obtained from subjects or their proxies, who could withdraw at any time.

\section{Author details}

'Department of Bone Marrow Transplantation, University of Duisburg-Essen, University Hospital Essen, West German Cancer Center, Hufelandstr. 55, Essen 45122, Germany. ${ }^{2}$ Department of Cardiology, University Hospital Essen, Essen, Germany.

Received: 2 September 2016 Accepted: 28 February 2017

Published online: 22 March 2017

\section{References}

1. Gramlich L, Kichian K, Pinilla J, Rodych NJ, Dhaliwal R, Heyland DK. Does enteral nutrition compared to parenteral nutrition result in better outcomes in critically ill adult patients? A systematic review of the literature. Nutrition. 2004;20(10):843-8.

2. Feng Y, Ralls MW, Xiao W, Miyasaka E, Herman RS, Teitelbaum DH. Loss of enteral nutrition in a mouse model results in intestinal epithelial barrier dysfunction. Ann NY Acad Sci. 2012;1258:71-7.

3. Ralls MW, Demehri FR, Feng Y, Woods Ignatoski KM, Teitelbaum DH. Enteral nutrient deprivation in patients leads to a loss of intestinal epithelial barrier function. Surgery. 2015;157(4):732-42.

4. Nguyen NQ, Ng MP, Chapman M, Fraser RJ, Holloway RH. The impact of admission diagnosis on gastric emptying in critically ill patients. Crit Care. 2007;11(1):R16.

5. Meenan J, Spaans J, Grool TA, Pals ST, Tytgat GN, van Deventer SJ. Altered expression of alpha 4 beta 7, a gut homing integrin, by circulating and mucosal T cells in colonic mucosal inflammation. Gut. 1997;40(2):241-6.

6. Liebregts T, Adam B, Bredack C, Gururatsakul M, Pilkington KR, Brierley SM, et al. Small bowel homing T cells are associated with symptoms and delayed gastric emptying in functional dyspepsia. Am J Gastroenterol. 2011; 106(6):1089-98. 
7. Oudemans-van Straaten HM, van der Voort PJ, Hoek FJ, Bosman RJ, van der Spoel Jl, Zandstra DF. Pitfalls in gastrointestinal permeability measurement in ICU patients with multiple organ failure using differential sugar absorption. Intensive Care Med. 2002;28(2):130-8.

8. Ukleja A. Altered Gl, motility in critically III patients: current understanding of pathophysiology, clinical impact, and diagnostic approach. Nutr Clin Pract. 2010;25(1):16-25.

9. Tarling MM, Toner CC, Withington PS, Baxter MK, Whelpton R, Goldhill DR. A model of gastric emptying using paracetamol absorption in intensive care patients. Intensive Care Med. 1997;23(3):256-60.

10. Moreira TV, McQuiggan M. Methods for the assessment of gastric emptying in critically ill, enterally fed adults. Nutr Clin Pract. 2009;24(2):261-73.

11. Kompan L, Kremzar B, Gadzijev E, Prosek M. Effects of early enteral nutrition on intestinal permeability and the development of multiple organ failure after multiple injury. Intensive Care Med. 1999;25(2):157-61.

12. Piton G, Belon F, Cypriani B, Regnard J, Puyraveau M, Manzon C, et al. Enterocyte damage in critically ill patients is associated with shock condition and 28-day mortality. Crit Care Med. 2013;41(9):2169-76.

13. Klaus DA, Motal MC, Burger-Klepp U, Marschalek C, Schmidt EM, LebherzEichinger D, et al. Increased plasma zonulin in patients with sepsis. Biochem Med (Zagreb). 2013;23(1):107-11.

14. Kanda T, Fujii H, Tani T, Murakami H, Suda T, Sakai Y, et al. Intestinal fatty acid-binding protein is a useful diagnostic marker for mesenteric infarction in humans. Gastroenterology. 1996;110(2):339-43.

15. Pelsers MM, Namiot Z, Kisielewski W, Namiot A, Januszkiewicz M, Hermens WT, et al. Intestinal-type and liver-type fatty acid-binding protein in the intestine. Tissue distribution and clinical utility. Clin Biochem. 2003;36(7):529-35.

16. Grootjans J, Thuijls G, Verdam F, Derikx JP, Lenaerts K, Buurman WA. Noninvasive assessment of barrier integrity and function of the human gut. World J Gastrointest Surg. 2010;2(3):61-9.

17. Johansson-Lindbom B, Agace WW. Generation of gut-homing T cells and their localization to the small intestinal mucosa. Immunol Rev. 2007;215:226-42.

18. Shibahara T, Miyazaki K, Sato D, Matsui H, Yanaka A, Nakahara A, et al. Alteration of intestinal epithelial function by intraepithelial lymphocyte homing. J Gastroenterol. 2005;40(9):878-86.

19. Engel DR, Koscielny A, Wehner S, Maurer J, Schiwon M, Franken L, et al. T helper type 1 memory cells disseminate postoperative ileus over the entire intestinal tract. Nat Med. 2010;16(12):1407-13.

20. de Jonge WJ, Van Den Wijngaard RM, The FO, ter Beek ML, Bennink RJ, Tytgat GN, et al. Postoperative ileus is maintained by intestinal immune infiltrates that activate inhibitory neural pathways in mice. Gastroenterology. 2003;125(4):1137-47.

21. Suto $G$, Kiraly A, Tache $Y$. Interleukin 1 beta inhibits gastric emptying in rats: mediation through prostaglandin and corticotropin-releasing factor. Gastroenterology. 1994;106(6):1568-75.

22. Lodato RF, Khan AR, Zembowicz MJ, Weisbrodt NW, Pressley TA, Li YF, et al. Roles of IL-1 and TNF in the decreased ileal muscle contractility induced by lipopolysaccharide. Am J Physiol. 1999;276(6 Pt 1):G1356-62.

23. Schwarz NT, Kalff JC, Turler A, Speidel N, Grandis JR, Billiar TR, et al. Selective jejunal manipulation causes postoperative pan-enteric inflammation and dysmotility. Gastroenterology. 2004;126(1):159-69.

24. Turler A, Kalff JC, Moore BA, Hoffman RA, Billiar TR, Simmons RL, et al. Leukocyte-derived inducible nitric oxide synthase mediates murine postoperative ileus. Ann Surg. 2006;244(2):220-9.

25. Feng $Y$, Teitelbaum DH. Tumour necrosis factor-induced loss of intestinal barrier function requires TNFR1 and TNFR2 signalling in a mouse model of total parenteral nutrition. J Physiol. 2013;591(15):3709-23.

26. Chapman MJ, Nguyen NQ, Deane AM. Gastrointestinal dysmotility: evidence and clinical management. Curr Opin Clin Nutr Metab Care. 2013;16(2):209-16.

27. Nguyen NQ, Bryant LK, Burgstad CM, Chapman M, Deane A, Bellon M, et al. Gastric emptying measurement of liquid nutrients using the (13)Coctanoate breath test in critically ill patients: a comparison with scintigraphy. Intensive Care Med. 2013;39(7):1238-46.

28. Nguyen NQ, Chapman MJ, Fraser RJ, Bryant LK, Burgstad C, Ching K, et al. The effects of sedation on gastric emptying and intra-gastric meal distribution in critical illness. Intensive Care Med. 2008;34(3):454-60.

29. Chapman MJ, Fraser RJ, Matthews G, Russo A, Bellon M, Besanko LK, et al. Glucose absorption and gastric emptying in critical illness. Crit Care. 2009; 13(4):R140.

30. Dolcetti R, Giardini R, Doglioni C, Cariati R, Pomponi F, D'Orazi C, et al. Alpha 4 beta 7 integrin expression is associated with the leukemic evolution of human and murine T-cell lymphoblastic lymphomas. Am J Pathol. 1997;150(5):1595-605.

31. Waldman E, Lu SX, Hubbard VM, Kochman AA, Eng JM, Terwey TH, et al. Absence of beta7 integrin results in less graft-versus-host disease because of decreased homing of alloreactive T cells to intestine. Blood. 2006;107(4): 1703-11.

32. Schnorfeil FM, Lichtenegger FS, Emmerig K, Schlueter M, Neitz JS, Draenert $R$, et al. T cells are functionally not impaired in AML: increased PD-1 expression is only seen at time of relapse and correlates with a shift towards the memory T cell compartment. J Hematol Oncol. 2015;8:93.

33. Lichtenegger FS, Lorenz R, Gellhaus K, Hiddemann W, Beck B, Subklewe M. Impaired NK cells and increased T regulatory cell numbers during cytotoxic maintenance therapy in AML. Leuk Res. 2014;38(8):964-9.

34. Bouteloup M, Perinel S, Bourmaud A, Azoulay E, Mokart D, Darmon M. Outcomes in adult critically III cancer patients with and without neutropenia: a systematic review and meta-analysis of the Groupe de Recherche en Reanimation Respiratoire du patient d'Onco-Hematologie (GRRR-OH). Oncotarget. 2017;8(1):1860-870.

\section{Submit your next manuscript to BioMed Central and we will help you at every step:}

- We accept pre-submission inquiries

- Our selector tool helps you to find the most relevant journal

- We provide round the clock customer support

- Convenient online submission

- Thorough peer review

- Inclusion in PubMed and all major indexing services

- Maximum visibility for your research

Submit your manuscript at www.biomedcentral.com/submit
Biomed Central 